Coimbra, C. \& Leitão, M. B.

"Das essências às multiplicidades: especialismo psi e produções de subjetividades"

\title{
DAS ESSÊNCIAS ÀS MULTIPLICIDADES: ESPECIALISMO PSI E PRODUÇÕES DE SUBJETIVIDADES
}

\author{
Cecilia Coimbra \\ Maria Beatriz Sá Leitão
}

Universidade Federal Fluminense

RESUMO: O presente artigo pretende colocar em análise a divisão social do trabalho no capitalismo, a emergência dos especialismos em especial o psi - algumas produçōes de subjetividades e parte de seus efeitos. Para tal, serão inicialmente apontadas algumas "formas" que vão sendo forjadas para o Homem, para a Sociedade, para a Psicologia e para Política através da crença de que possuem uma essência, uma existência em si. Tal crença tem instituído uma psicologia essencialista, privatista/intimizante e familiarista. Outro aspecto priorizado é a produção do "modo-de-ser-indivíduo' e alguns de seus efeitos: a meritocracia e a psicologização da vida social. Finalizando, serão apontados escapes, derivas e linhas de fuga que permitem pensar o homem e a sociedade, a psicologia e a política não como territórios excludentes, mas como campos conectados que se atravessam e se constituem.

PALAVRAS-CHAVE: especialismo psi, produções de subjetividades, multiplicidades.

\section{FROM ESSENCES TO MULTIPLICITIES: PSYCHOLOGY SPECIALISM AND SUBJETCTIVITY PRODUCTIONS}

ABSTRACT: The present article is intended as an analysis of the social division of work within Capitalism, the emergence of specialization - mainly psychology specialization - some productions of subjectivities and part of its effects. For such, we will initially appoint some "forms" that are being made for Man, Society, Psychology and Politics through the belief they have an existence of their own. Such belief has instituted an essencialist psychology, privatized/intimized and family-focused. Another prioritized aspect 
is the production of the "individual-way-of-being" and some of its effects: meritocracy and the psychologizing of social life. Finally, some escape routes will be pointed out and escape lines that will allow the thinking of Man, Society, Psychology and Politics not as self-excluding territories, but as interconnected fields that crisscross out and add together.

KEYWORDS: psychology specialism, subjectivity productions, multiplicities

"Era ele que erguia casas

Onde antes só havia chão.

Como um pássaro sem asas

Ele subia com as casas

Que lhe brotavam da mão.

Mas tudo desconhecia

De sua grande missão:

Não sabia, por exemplo

(...)

Que a casa que ele fazia

Sendo a sua liberdade

Era a sua escravidão.

(...)

Mas ele desconhecia

Esse fato extraordinário:

Que o operário faz a coisa

E a coisa faz o operário

(...)"

(O Operário em Construção - Vinícius de Moraes)

Como o "operário em construção" vivemos, também cotidianamente, no campo do desconhecimento onde tudo parece, às vezes, opaco, quando a luminosidade dos flashes cega, onde parece que o olhar se turva, diante do que é tão superfície e tão visível. Potência de ver temos constantemente, entretanto, desconhecimentos de muitas produções em nós e no mundo... 
Coimbra, C. \& Leitão, M. B.

"Das essências às multiplicidades: especialismo psi e produções de subjetividades"

Dentre os diferentes dispositivos produzidos pelo sistema capitalista, por exemplo, ressaltamos a divisão social do trabalho, que irá instituir e naturalizar dois territórios muito bem definidos. O primeiro, o do saber-poder, é identificado como o lugar da competência, do conhecimento/reconhecimento, da verdade, dos modelos, da autoridade, do discernimento, da legitimidade e adequação de certos modos de ser. O segundo, o do não saber, o da falta, caracterizado como território da exclusão, visto ser desqualificado, condenado, segregado, considerado, até mesmo, como danoso e perigoso - o campo do desvio - necessitando sistematicamente ser acompanhado, tutelado, monitorado e controlado.

A divisão social do trabalho, a designação dos individuos a seus postos de produção não dependem unicamente dos meios de coerção ou do sistema de remuneração monetária; mas também, e talvez de modo mais fundamental, das técnicas de modelização dos agenciamentos inconscientes operados pelos equipamentos sociais, pelos meios de comunicação, pelos métodos psicológicos de adaptação de todos os tipos (GUATTARI, 1981:171).

Pensar no trabalho que nós, psicólogos, temos desenvolvido é pensar neste lugar instituído e naturalizado, percebido como ahistórico, neutro e objetivo que nós, muitas vezes, temos ocupado e fortalecido: o do saber-poder.

Entendemos, assim como Rolnik e Guattari (1986), que a ordem capitalistica produz os modos das relações humanas até em suas representaçôes inconscientes: os modos como se trabalha, como se é ensinado, como se ama, como se trepa, como se fala, etc. Ela fabrica a relação com a produção, com a natureza, com os fatos, com o movimento, com o corpo, com a alimentação, com o presente, com o passado e com o futuroem suma, ela fabrica a relação do homem com o mundo e consigo mesmo. Aceitamos tudo isto porque partimos do pressuposto de que esta é a ordem do mundo, ordem que não pode ser tocada sem que se comprometa a própria idéia de vida social e organizada (grifo dos autores, p.42).

Estas formas de dominação enunciadas acima, não se manifestam de maneira tão simples e transparentes como quando pensamos as relaçóes dominador $\mathrm{x}$ dominado, opressor $\mathrm{x}$ oprimido, senhor $\mathrm{x}$ escravo. Sem negar a importância dessas perspectivas, podemos pensá-las de outro modo: 
desde os múltiplos e diferentes atravessamentos que as constituem e que delas fazem parte. Estes podem ser lidos enquanto produçóes de subjetividades, onde não há oposição entre as relações econômicas de produção e relações de produção subjetivas. As duas se constituem em um único processo, pois o que faz a força da subjetividade capitalística é que ela se produz tanto no nivel dos opressores quanto dos oprimidos (ROLNIK \& GUATTARI: 44)

São, portanto, essas produções de subjetividades que constróem e definem as formas de pensar, perceber, sentir e agir no mundo, sendo forjadas pelos diferentes equipamentos sociais. Dentre eles, as práticas psicológicas.

Haverá escape, principalmente tendo em vista a massificação dos meios de comunicação na sociedade atual de controle globalizado? Apesar de estarmos imersos neste mundo, independente da classe social a que estejamos vinculados, há possibilidades de produzir rupturas, derivas, outras construções e conexōes, outras subjetividades que não as hegemônicas. Este é o campo da criação e invenção, por excelência.

Segundo, portanto, esta concepção, não entendemos o sujeito como possuidor de uma natureza ou essência. Ao contrário, ele é produzido e produtor, nunca pensado como algo acabado, mas em constante movimento e, assim, com ilimitadas possibilidades de ser.

Enquanto produzido e produtor de subjetividades, o território do saber-poder aponta, dentre outras, para algumas construçóes, como a da essencialidade e "o modo-de-ser-indivíduo". ${ }^{1}$ Estas crenças são fortes expressões do capitalismo, com sua referência idealista-metafísica, presentificadas na ordem político-social. Um de seus traços são os especialismos, dos quais, nos interessam aqui, as práticas psi: estas e suas estratégias, que têm funcionado como mantenedoras e, mesmo, fortalecedoras do status-quo.

\section{DANDO FORMAS AO MUNDO}

A abordagem idealista-metafísica vem a ser, desde a antiguidade - aliada, nos tempos modernos, ao racionalismo - a forma de pensar predominante no Ocidente. ${ }^{2}$ Esse pensamento, herança da filosofia

1 Termo utilizado por Barros, R.D.B (1994).

2 Sobre o assunto consultar Veyne, P. (1982) e Fuganti, L. A (1990). 
Coimbra, C. \& Leitão, M. B.

"Das essências às multiplicidades: especialismo psi e produções de subjetividades"

platônica, concebe a existência de dois mundos: o das essências e o sensível. Aquele se reporta à verdade, aos modelos, à perfeição, aos ideais únicos, universais, eternos. O mundo sensível seria o mundo das sensaçôes, dos sentidos, aquele que habitamos. Aqui, estariam os simulacros, as cópias degradadas dos modelos ideais, que jamais poderiam ser atingidos. Poderíamos tentar aproximarmo-nos desse mundo da perfeição, através da filosofia e da ciência...

Uma certa leitura do marxismo - através de uma análise crítica das influências idealistas-metafísicas, bem como a de Foucault e, também, a da Filosofia de Diferença, trazem, na contemporaneidade, questionamentos ao platonismo. Estes últimos construirão rupturas, também, com o racionalismo.

Tal contraponto vem afirmar a importância das práticas sociais na produção dos objetos, saberes e sujeitos. Todos eles não teriam uma existência em si, não seriam um "être-lá", mas estariam sendo produzidos historicamente por práticas datadas e localizáveis, que os objetivam. Trata-se de um processo, aliás, de muitos processos: provisórios, múltiplos e diversos.

A crença nas essências, um dos pilares das subjetividades hegemônicas no capitalismo, também estará presente nas práticas psi. O solo de emergência dessas práticas foi o capitalismo industrial também chamado por Foucault de sociedade disciplinar. ${ }^{3}$

Para pensar a questão da essência na prática dos psicólogos, priorizaremos, dentre outros objetos, o homem, a sociedade, a psicologia e a política.

A concepção de homem hegemônica na psicologia é de um ser ahistórico, abstrato, tendo uma existência em si e que se refere ao homem que pergunta: quem sou eu ? Qual é o meu desejo ? Por que desejo? ${ }^{4}$ Pretende-se, com isso, chegar a uma verdade sobre si, a um essencialismo.

Da mesma forma, a psicologia pergunta: quem é esse homem? Como e qual é o seu mundo interno ? E o seu íntimo ? Acreditando que tem possibilidade de atingir o âmago do ser - nomeado sujeito -, a

3 Sobre o assunto consultar Foucault (1974 e 1988)

4 A constante utilização da expressão 'por que" reporta a uma concepção de causa, origem primeira e determinação em última instância, o que configura o território da essência. 
psicologia vai produzindo um determinado modo de ser humano. Ironicamente esse homem também é pensado como o homem do livre arbítrio...

Essa concepção de homem intimizado, ${ }^{5}$ preocupado com o auto-conhecimento e auto-realização emerge no mesmo contexto histórico - meados do século XIX - em que também se forja um determinado modelo de família e de lar. Esse território é o lugar do refúgio, do íntimo, do privado, em oposição ao espaço público. Tentase preservar o eu que o exterior parece desintegrar. O território do público não é só desqualificado e esvaziado, mas é identificado como o lugar do perigo, das doenças, da barbárie. As ruas devem ser evitadas; os coletivos despertam desconfiança.

Nesse contexto, a família nuclear e o lar burguês passam a ser os territórios da segurança, da afetividade e da saúde. As dicotomias que opõem o público ao privado, o interior ao exterior, o homem à sociedade são instituídas. Criam-se determinadas essências e modelos de homem, de família e de sociedade.

A concepção de sociedade que emerge também possuirá uma essência onde o homem é o lobo do homem, a competição faz parte de sua existência, a violência nas relaçôes em geral é vista como intrínseca à esta sociedade. Hoje, no neoliberarismo, com seus corolários de globalização, algumas outras naturalizações vêm sendo produzidas, tais como: Estado mínimo, nova ordem mundial, leis do mercado, competitividade, flexibilização, livre comércio, privatizaçōes, eficiência, eficácia.

Essas essências atribuídas ao homem e à sociedade irão instituir uma psicologia também essencialista, privatista/intimizante e familiarista. Tal território se apresenta neutro, científico, objetivo, mensurável, definitivo e com poder de previsão. Essas naturezas atribuídas à psicologia se opõem ao campo político que é caracterizado como não científico, implicado e, portanto, não neutro. A psicologia, então, em sua pureza, não pode ser conspurcada pelo político. Ainda hoje, em alguns cursos de formação, trabalhos vinculados a questôes sociais são percebidos como atuações políticas, que não deveriam estar relacionados à psicologia. Curiosamente, em alguns discursos psi, a dimensão social é mencionada, mas de forma abstrata, ahistórica

5 Sobre o assunto consultar Sennett (1988) 
Coimbra, C. \& Leitão, M. B.

"Das essências às multiplicidades: especialismo psi e produções de subjetividades"

ou dissociada, mantendo-se a oposição psicologia e política. Está configurado um território, um domínio de saber onde o poder considerado neutro - do especialista se faz exercer.

A crença nas essências produz a reificação do indivíduo. $\mathrm{O}$ "modo-de-ser indivíduo" onde tudo será responsabilidade e atributo do sujeito é, entretanto, apenas uma das formas possíveis de subjetividade em nosso mundo. Ela expressará duas características bem caras ao modo de funcionamento capitalista. Uma delas é a meritocracia, onde tudo depende da capacidade e da eficiência individual. Cada um passa a ser responsável pelo que é e pelo que consegue fazer. Hoje, no neoliberarismo, exige-se que esse homem seja cada vez mais flexível. ${ }^{6} \mathrm{O}$ fracasso e o sucesso são, então, consideraçôes individuais associadas ao bem e ao mal. ${ }^{7}$

A par da meritocracia temos a psicologização da vida social desse indivíduo, quando o que acontece é remetido para o campo das explicações psicológico-existenciais. O cotidiano é esvaziado politicamente; as relações de opressão, as explorações, as diversas formas de dominação são invisibilizadas e atribuídas ao território do psicológico, fazendo parte do psiquismo e da vida interior do sujeito. Com forte apoio de argumentos moralistas - tão ao gosto do higienismo do início do século XX - transformam-se em conflitos, sonhos, ilusões, fantasias e, mesmo, patologias. Estas, não somente são atribuídas ao indivíduo, mas estendidas especialmente a determinados segmentos sociais, como a pobreza ${ }^{8}$ e a todos aqueles que destoam das normas e modelos instituídos. Ou, ainda, aos que reproduzem essas normas de modo ruidoso e, mesmo, incômodo.

Uma das estratégias utilizadas pelas práticas psi é o que Rolnik (1989) chama de "síndrome da carência-captura" onde ao discurso da falta e da desqualificação associa-se a imposição de modelos. Cabe ao especialista preencher e/ou assinalar a existência dessa lacuna ou déficit. Cabe a ele induzir - muitas vezes, através das interpretações - o outro a conviver com a falta, a aceitá-la; às vezes, preenchê-la com o que é "adequado" e ser "como deve ser".

6 Sobre o Assunto consultar Sennett, R. (1999)

7 Utilizamos, aqui, os termos bem e mal ao invés de bom e ruim. Aqueles se reportam a noçōes modelares e definitivas. Estes apontam para o momento, para os acontecimentos, para a provisoriedade.

8 Sobre o assunto consultar Coimbra (2001). 
No Brasil, tais crenças na essência e no "modo-de-ser-indivíduo" foram fortalecidas e amplamente divulgadas no período da ditadura militar, a partir do final dos anos 60, quando ocorreu o "boom" da psicologia, da psicanálise e das faculdades particulares. Naquele momento, vivíamos em pleno terrorismo de Estado, em um clima de "Brasil grande", onde essas concepções de homem, de família, de lar, de rua, de sociedade, de psicologia e de política, dentre outras, muito serviram nas tentativas de cristalização da dominação e da interceptação dos desejos, das invenções e criações. Tudo o que escapasse às formas de interiorização naturalizadas, era considerado perigoso, acompanhando as subjetividades vinculadas à Doutrina de Segurança Nacional então vigente. Como tal tudo isso deveria ser evitado e banido. Naquele momento, duas categorias de acusação sobre a juventude foram produzidas: a do subversivo e a do drogado. ${ }^{10}$ Ambas consideradas danosas, já que colocavam em análise a ênfase dada ao espaço privado, ao modelo de família sadia e estruturada e seus sonhos de ascensão social, à rua vista como lugar do perigo, à desqualificação e esvaziamento dos espaços públicos. Da mesma forma, as crenças na identidade, no homogêneo e no definitivo se fortaleciam nas práticas psi.

\section{DESFORMANDO O MUNDO}

É preciso transver o mundo.

Isto seja:

Deus deu a forma. Os artistas desformam..

É preciso desformar o mundo.

Tirar da natureza as naturalidades.

Fazer cavalo verde, por exemplo.

Fazer noiva camponesa voar - como em Chagall.

Agora é só puxar o alarme do silêncio

Que eu saio por ai a desformar."

(As Lições de R.Q. - Manuel de Barros)

9 Sobre o assunto consultar Coimbra, C.M.B. (1995).

10 Sobre o assunto consultar Velho, G. (1987). 
Coimbra, C. \& Leitão, M. B.

"Das essências às multiplicidades: especialismo psi e produções de subjetividades"

As problematizações que aqui trazemos remetem-nos ao campo das invençōes, das mudanças, ao campo dos desafios. Trata-se de um território assumido como político onde as lutas se fazem cotidianamente. Ao entendermos o homem e a sociedade, a psicologia e a política como territórios produzidos historicamente que não se opõem, mas que se atravessam e se constituem, estamos afirmando uma relação com o tempo-acontecimento, sempre provisória e múltipla; produção de devires, de-vir-a ser, de fluxos mutantes.

Não tendo uma natureza, o homem, a sociedade, a psicologia e a política não são. Sempre estão sendo, sempre estarão se fazendo. Renunciamos, portanto, aos modelos, às identidades, às permanências, às homogeneidades. Estamos, com isso, afirmando as especificidades dos diferentes e diversos saberes que se encontram no mundo; especialmente alguns que têm sido secularmente desqualificados e, mesmo, ignorados pela arrogância daqueles hegemônicos, nomeados como oficiais e, por isso, produzidos como verdadeiros, únicos, universais, totalizantes. ${ }^{11}$ Ao afirmarmos esses saberes específicos estamos abandonando as hierarquias, os cristalizados, duros e inflexíveis limites que tentam demarcar os sagrados territórios de cada um desses saberes, que tentam isolá-los e, portanto, hierarquizá-los. Estamos apontando para uma proposta transdiciplinar onde todos esses saberes estejam presentes, possam misturar-se e "contaminar" uns aos outros. Aqui, interessa a apropriação da capacidade de movimentar-se, a possibilidade de sempre transitar, de ignorar cercas, rearrumar e criar outros territórios.

Pensar dessa forma traz efeitos para nossas práticas enquanto psicólogos: de especialistas a interventores/agenciadores. Essa proposta é, sem dúvida, um compromisso político que aposta na criação e na mudança, em formas diversas de existência, de sociabilidade. Trata-se de afirmar as potências, as diferenças, as multiplicidades e possibilidades finitas e ilimitadas do homem, da sociedade, da psicologia e da política. A aposta na produção de "verdades" sempre provisórias, temporais e temporárias, nas "paixões alegres", num "mundo onde caibam muitos outros mundos". ${ }^{12}$

11 Sobre o assunto consultar Foucault (1988b).

12 Referimo-nos ao slogan utilizado no III Fórum Social Mundial, realizado em Porto Alegre, em 2003 e também, frase ouvida pelas autoras no acampamento de paz de Oventic, em 2002, criado e administrado pelo Exército Zapatista de Libertação Nacional (EZLN), Chiapas México. 
Referimo-nos, aqui, à utopia, mas às utopias ativas, onde tudo está se fazendo, onde tudo pode ser.

As poéticas palavras do Sub-Comandante Marcos, um dos portavozes do movimento zapatista, e de Joaquim Sabina, apontam para essas utopias.

"Como si llegaram a buen puerto mis ânsias,

Como si hubiera donde hacerce fuerte,

Como si hubiera por fin destino para mis pasos.

(...)

Como traerse al hoy cada mañana,

Como lo imposible por fin hecho,

Como si alguién de veras me quisiera,

Como si al fin un buen poema me saliera...

Una oración.

Como si la arena cantara en el desierto

Los cantos de sirena de mar Muerto,

Como si para crecer sobraran las escaleras,

Como si escribiera un ciego un libro abierto.

Ven a poblar el zócalo de ojos,

Siembra de migas de pan caliente

Mis canas de alcanfor adolescente.

Ponte al sordo voz y alas ao cojo,

Bendice nuestro arroz, nuestro minuto,

Como si no fuéramos cúmplices del luto...

Del corazón."

(Como un dolor de muelas, Marcos, Sabina e Varona).

\section{REFERÊNCIAS}

BARROS, R.D.B. Grupo: a afirmação de um simulacro. São Paulo, Tese de doutorado, PUC, 1994.

BARROS, M. Livro Sobre Nada. São Paulo/Rio de Janeiro: Record, 1997. 
Coimbra, C. \& Leitão, M. B.

"Das essências às multiplicidades: especialismo psi e produções de subjetividades"

COIMBRA, C.M.B. Guardióes da Ordem: uma viagem pelas práticas psi no Brasil do 'milagre'. Rio de Janeiro: Oficina do Autor, 1995.

COIMBRA, C.M.B. Operação Rio: o mito das classes perigosas. Rio de Janeiro: Oficina do Autor/Intertexto, 2001.

FUNGANTI, L. A. Saúde, Desejo e Pensamento in Saúde Loucura, n o 2. São Paulo: Hucitec, 1990, 19-82.

FOUCAULT, M. A Verdade e as Formas Jurídicas. Rio de Janeiro: Cadernos da PUC n o 16, 1974.

FOUCAULT, M. Vigiar e Punir. Rio de Janeiro: Graal, 1988A.

FOUCAULT, M. Microfisica do Poder. Rio de Janeiro: Graal, 1988b.

GUATTARI, F. Revolução Molecular: as pulsações políticas do desejo. São Paulo: Brasiliense, 1981.

GUATTARI, F. \& ROLNIK, S. Micropolitica: cartografias do desejo. Petrópolis: Vozes, 1986.

MORAES, V. Antologia Poética. Rio de Janeiro: José Olímpio, 1975.

ROLNIK, S. Cartografia Sentimental: transformaçôes contemporâneas do desejo. São Paulo: Estação Liberdade, 1989.

VELHO G. Individualismo e Cultura: notas para uma antropologia da sociedade contemporânea. Rio de Janeiro: Jorge Zahar, 1987.

VEYNE, P. Foucault Revoluciona a História in Como Se Escreve a História. Brasília: Cadernos da UNB, 1982.

SENNETT, R. O Declinio do Homem Público: as tiranias da intimidade. São Paulo: Companhia das Letras,1988.

SENNETT, R. A Corrosão do Caráter. São Paulo/Rio de Janeiro: Record, 1999. 


\section{DISCOGRAFIA UTILIZADA}

Marcos, S; Sabina, J. e Varona, P. Como um dolor de muelas in Sabina, J. Dimelo em la Calle. Madrid: BMG Music Spain S.A, 2002 .

Cecília Maria Bouças Coimbra, é Psicóloga, Professora Adjunta da Universidade Federal Fluminense, Vice-presidenrte do Grupo Tortura Nunca Mais/RJ O endereço eletrônico da autora é: gtnm@alternex.com.br

Maria Beatri Sá Leitão, é Socioanalista e Psicanalista, membro da Equipe ClínicoGrupal Tortura Nunca Mais do Grupo Tortura Nunca Mais/RL.

O endereço eletrônico da autora é: gtnm@alternex.com.br

\section{Cecília Coimbra e Maria Beatriz Sá Leitão}

Das essências às multiplicidades: especialismo psi e produções de subjetividades Recebido: $18 / 6 / 2003$

$1^{\text {a }}$ revisão: $9 / 9 / 2003$

Aceite final: 1/10/2003 